\title{
LII. Some experiments made with a view to the detection and prevention of frauds in the sale of skimmed milk; together with an account of a simple lactometer for effecting that purpose
}

\section{Edmund Davy Esq}

To cite this article: Edmund Davy Esq (1821) LII. Some experiments made with a view to the detection and prevention of frauds in the sale of skimmed milk; together with an account of a simple lactometer for effecting that purpose , Philosophical Magazine Series 1, 58:282, 241-247, DOI: $10.1080 / 14786442108652614$

To link to this article: http://dx.doi.org/10.1080/14786442108652614

曲 Published online: 27 Jul 2009.

Submit your article to this journal ๘

Џ Article views: 2

Q View related articles $\sqsubset$ 


\section{$\left[\begin{array}{ll}241 & ]\end{array}\right.$}

LII. Some Experiments made with a viow to the Delectiom and Prevention of Frauds in the Sale of skimmed Milk; together with an Account of a simple Lactometer for effecting that Purpose. By EDmund Davy, Esq. Professor of Chemistry and Secretary to the Royal Cork Institution.

Skrmmed milk, as is well known, is used to a very great extent in Ireland, and especially in the South *, where it forms an indispensable part of the subsistence of the lower orders. Potatoes and skimmed milk, indeed, constitute almost their sole, or at least their principal food. It is therefore of much importance, that an article which essentially contributes to the support of a very large portion of the community, should be supplied in a genuine unadulterated state. Unfortunately this has not been the case. Much of the skimmed milk exposed for sale in our milk markets, has been largely adulterated with water; and for want of the means of detection, this fraud has been practised with impunity, not only in Cork, but also in other parts of the country. An unsuccessful attempt had been made to remedy this evil. Persons called tasters were appointed to inspect the milk markets in Cork, and empowered to detain such milk as they supposed to be adulterated. But the inadequacy of such a mode of prevention must be apparent; for nothing can be more vague and uncertain than decisions founded upon the mere taste and appearance of milk. In consequence of the total incompetency of tasters, to prevent the commission of frauds in the sale of skimmed milk, a Committee composed of respectable farmers, \&c. was formed for the express purpose of putting a stop to this disgraceful practice, so injurious both to the poor, and to the fair dealer. The Committee waited upon our active chief magistrate Sir Anthony Perriere, knt., to apprize him of their intention, and to solicit his assistance. Anxious to co-operate with the Committee in promoting a measure of acknowledged public utility, Sir Anthony afforded every assistance in his power, and promised to adopt any practical remedy which should be devised. At his suggestion, the Committee consulted me as to the best means of carrying their design into execution, and in compliance with their request, I directed my best attention to the consideration of the subject. An instrument on the principle of the hydrometer, seemed to promise the simplest means that could be employed for the detection and prevention of frauds in the sale of skimmed milk; but whether it was practicable to construct such an instrument, depended upon circumstances which could

* The sale of skimmed milk in the markets of Cork alone, I am informed, amounts to about $1000 l$. per week.

Vol.58. No. 282. Oct. 1821.

H h only 
only be determined by experiment. In order to satisfy myself on this point, I commenced a series of experiments on skimmed milk in February last, which have, with occasional interruptions, occupied me ever since. I did not at first indulge anv sanguine expectations as to the result of $m y$ investigation; but after I had carefully made above a hundred experiments upon geniine skimmed milk procured from many of the principal dairy farms, embracing all the varieties of cattle, soil, and modes of feeding, common to this part of the country; and also examined many specimens of adulterated skimmed milk from the markets, I have at length ventured to construct a simple lactometer (on the well known principle of the hydrometer), the use of which, I have no doubt, will effectually prevent the frauds now practised in the sale of skimmed milk.

Before I describe this instrument, it may be proper briefly to notice the circumstances which led to its coustruction. My first experiments were directed to ascertain whether any uniformity exists in the density of different specimens of genuine skimmed milk; accordingly I procured this article from many of the principal dairy farms, and from private houses in the neighbourhood. I also obtained new milk from the same sources, which I skimmed myself, after suffering the cream to remain on it about the usual time. The greater number of those specimens were of the specific gravity 1.037 and 1.0375 . Some were higher, but the highest was 1.040 , and the lowest 1.036 , the thermometer being at $50^{\prime}$. These experiments, confirmed by others which I afterwards made, led me to conclude that a considerable degree of uniformity prevails in the density of genuine skimmed milk; and this uniformity, I presume, would be still greater, if due allowance were made for accidental circumstances connected with the experiments, which, though not easy to appreciate, must, to a certain extent, influence the specific gravity of milk; as for example, slight variations of temperature and of the balance emploved; to which must be added the unequal exposure to the atmosphere of the several specimens of milk examined. In reference to this iast particular, it is proper to state that I found only one specimen of milk of so high a specific gravity as 1.040 ; and in this instance the cream had been suffered to remain on the milk for above three days, and its specific gravity was not taken until some hours after it bad been skimmed. These circumstances incline me to refer its superior density to evaporation, owing to protracted exposure to the atmosphere.

After I was satisfied concerning the degree of uniformity which exists in the density of genuine skimmed milk, my next object was to examine the skimmed milk brought to the markets in Cork, in order to ascertain the nature of the adulterations practised 
in the sale of this article. Accordingly, I procured at different times, a great number of specimens from the nilk markets; and on submitting them to a eareful examination, I found that some were genuine, and of course corresponded with good skimmed milk in every particular. Others were adulterated in different degrees, but the only foreign substance I could detect in the adul terated specimens, was water. By adding a certain quantity of water to genuine skimmed milk, it became of the same density as the adulterated milks from the markets. By simple distillation, the adulterated milks furnished pure water, and became of the same density as genuine inilk. In some cases, I found skimmed milk from the markets adulterated with more than one-fifth of water; in other instances, with about one-sixth, one-seventh, and oneeighth of water. The worst of the adulterated milks from the markets was of the specific gravity $1 \cdot 026$, the highest of the genuine milks from the markets was $1 \cdot 039$, the thermometer being at $50^{\circ}$.

It is, I believe, a common opinion that skimmed milk is adulterated with other substances besides water; as for example, chalk, flour, starch, sugar, \&c. which are said to be used for the purpose of concealing the water, by communicating as circumstances may require a certain degree of whiteness, thickness, or sweetness to milk. I have made a number of experiments to ascertain the correctness of this notion, and I am convinced the opinion is not well founded. Chalk is perfectly insoluble in skimmed milk, and soon subsides when mixed with it, on account of its superior density. Flour and starch increase the density of skimmed milk, but this effect is only temporary; for, not being soluble, they gradually subside. The high price of sugar, were there no other consideration, precludes its use ; for I have found by experiment that it would be too expensive even if it could be procured at the low rate of four-pence per pound.

Those experiments on the density of genuine and adulterated slimmed milk (already noticed), which were made at the temperature of $50^{\circ}$, I have since repeated at $60^{\circ} \mathrm{Fahr}$. with similar results, making due allowance for the difference of temperature. I have examined the density of a great number of different specimens of genuine skimmed milk, but have not found any of a lower specific gravity than 1.035 at $60^{\circ}$ of Fahrenheit.

All my experiments concur to prove, that in the neighbourhood of Cork, genuine skimmed milk obtained under nearly similar circumstances, varies comparatively but little in its density; and that the only substance used to adulterate this article for the markets in Cork, is water.

Skimmed milk and water combine without undergoing any sensible alteration of volume, or condensation. Skimmed milk H h 2 
is of much greater specific gravity than water, and its density is diminished in direct proportion to the quantity of water added to it. On those facts the lactometer I have made depends; it is exclusively adapted to skimmed milk, in which respect, as well as in simplicity of construction, it differs from the ingenious instrument of Mr. Dicas.

\section{Description of the Lactometer, E्c.}

This instrument (as will appear from the accompanying plate) differs but little in form from the common hydrometer. Its di stinction is to be found in its seale, which is adapted to skimmed milk. It is made of brass, and consists of a pear-shaped bulb, at the top of which is a graduated stem, and at the bottom a brass wire to the end of which a weight is screwed. The scale begins about three-fourths of an inch from the bottom of the stem, and is marked 0 , which corresponds with the specific gravity of the lightest genuine skimmed milk, or $1 \cdot 035$, distilled water being 1.000. The dots and figures which extend from 0 to 35 , indicate "parts of water in 100 parts skimmed milk at $60^{\circ}$," as is engraved on the reverse of the stem, and has been ascertained by experiment. The instrument is constructed for the temperature of $60^{\circ}$ of Fahr., a point judged the most convenient, as it agrees very nearly with the temperature of the milk brought to our markets during the summer. As all fluids expand by heat and contract by cold, in using the lactometer an allowance must be made of $l^{\circ}$ on the instrument for every $3^{\circ}$ of temperature, that the milk under examination is either above or below $60^{\circ}$ of Fahr. Thus the lactometer, which would remain at 0 in milk of the temperature of $60^{\circ}$, would sink $1^{\circ}$ below 0 , if the temperature of the milk were increased to $63^{\circ}$, $2^{\prime \prime}$ if it were raised to $66^{\circ}, 8 \mathrm{c}$. And on the contrary, if the temperature of the same milk were reduced to $57^{\circ}$, the instrument would then experience a rise above 0 equal to $1^{\circ}, 8 \mathrm{c}$. This lactometer is made by Mr. Bennett, mathematical instrument maker, Cork, and sold in a tin case, either with or without a small thermometer. It is scarcely necessary to give directions for using so simple an instrument. All that is required is, to fill the tin case with the milk to be examined, immerse the lactometer in the milk, and observe the point at which it remains stationary after it rises. Note also the temperature of the milk, and, if necessary, make the allowance directed for expansion or contraction of volume.

Before this lactometer was used in the milk markets, experiments were made with it in the presence of the Mayor of Cork, Sir A. Perriere, Kut., the Committee of whom 1 have spoken, and other gentlemen, who expressed themselves satisfied with 
the accuracy and delicacy of the instrument. The first morning it was employed in the milk markets of Cork, the Mayor, some of the Committee and myself attended, when the Mayor seized thirty-eight churns of skimmed nilk, containing above 2000 pottles. The lactometer stood in most of it at $20^{\circ}$; the thermometer being at $58^{\circ}$, which indicated about one-sixth of water. In the evening of the same day, we again visited the very same markets, but found the milk in all of them so much improved that not a single churn was seized. Shortly after, a special public Meeting of the Farmers and Dairymen who supply the markets with milk was summoned, at which the Mayor of Cork presided. In the presence of the Meeting he made several experiments with the lactometer, which were deemed satisfactory. The Mayor then directed the Market Jurors in future to employ the lactometer in the milk markets, and to detain all skimmed milk, in which the instrument sunk $5^{\circ}$ below 0 , or the point which represents genuine skimmed milk of lowest density. This allowance of $5^{\circ}$ was made to avoid being too strict, on the first use of the new instrument. Since the lactometer was first used in the milk markets, the skimmed milk exposed for sale in Cork has been materially improved in quality; and hence comparatively few seizures have been made, though the instrument has now been employed above two months. Dairymen, who have once forfeited their milk, now find they can no longer water it with impunity, and are beginning to relinquish the practice. The same dairy farms, which lately sent milk to the markets in which the lactometer stood at $20^{\prime}$, now furnish milk in which the instrument stands at 0 . Besides the evidersce already adduced that water is the only substance used to adulterate skimmed milk in this neighbourhood, the fact has been repeatedly admitted by those concerned in the sale of this article. I have been credibly informed that persous have been hired for the purpose of watering milk, and that in this way hundreds and even thousands of pounds have been annually pocketed. This fraud has hitherto been suffered with impunity, merely for want of some simple means of detection. It is every where so easy and practicable, and may be carried to a great extent without being perceptible to the taste or appearance, though it may be readily dis covered by means of the lactometer, which is well adapted, not only for markets where skimmed milk is sold, but also for all public establishments where it is used in large quantities.

I think it proper to state, why the scale of the lactometer has not yet been extended above 0 , though a vacant space remains on the stem for this purpose, as may been by a reference to fig. 1, (l'l. IV.)

Fig. 1. The lactometer.

Fig. 2. The reverse of the stem.

Fig. 3. 
Phil.Mag.Vol. LVUI Pl. t)

Fig. 3.

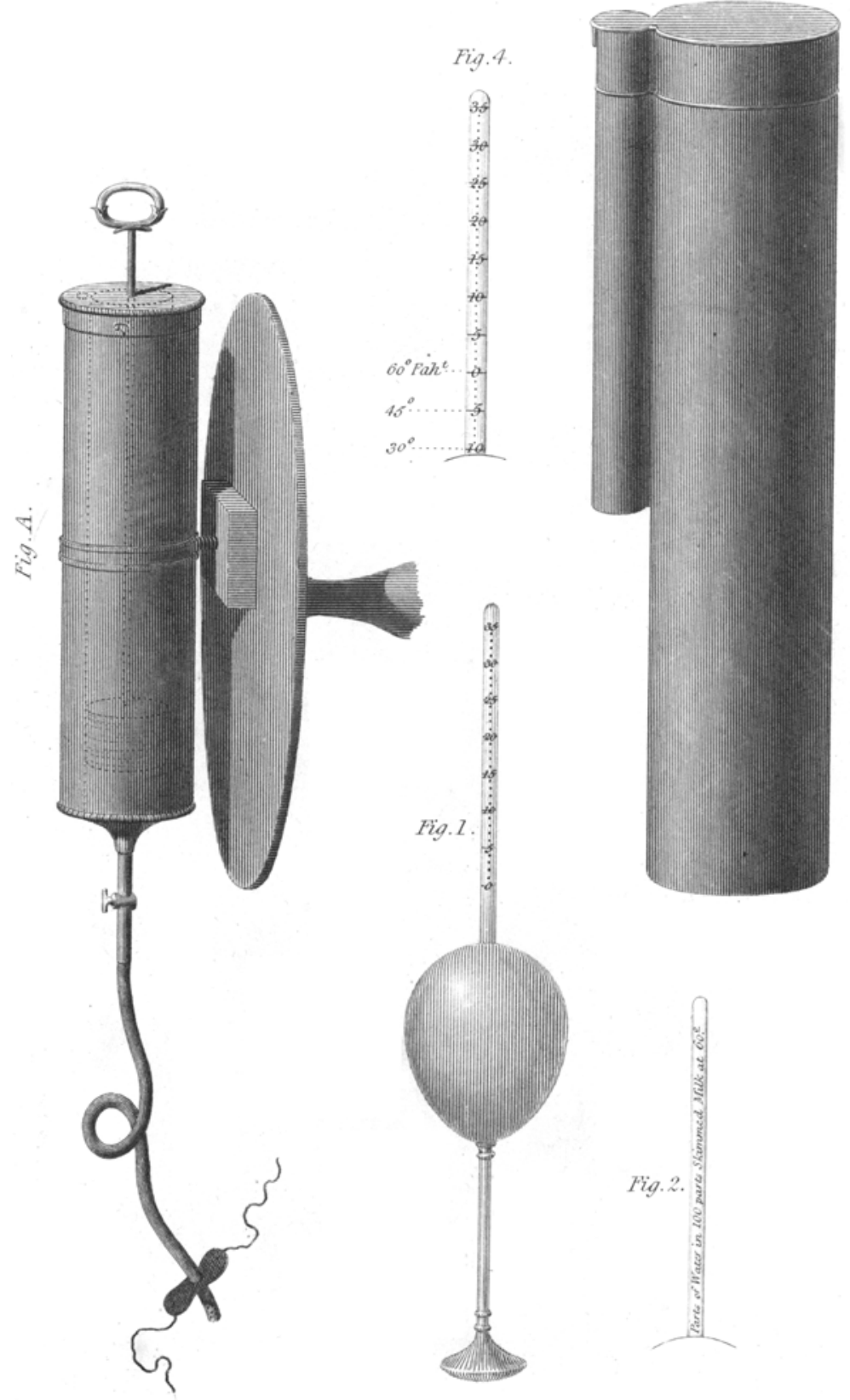


Fig. 3. The tin case with a small case attached to it for a thermometer.

Fig. 4. The stem of fig. I, with the scale extended as it should be to $10^{\circ}$ above 0 .

My design at first was to make the instrument so simple, as to afford the means of detecting water in skimmed milk, at all seasons of the year, without the aid of a thermometer; an object which, with a little explanation, I think it capable of effecting to a sufficient degree of nicety for most practical uses. As the lactometer is constructed for the temperature of $60^{\circ}$ of Fahr., and every degree on its scale is equal to 3 degrees of Fahr., an allowance of 2 or 3 degrees below 0 would be amply sufficient for our warmest summer weather. For though the temperature of the air in this season is often much higher than $60^{\circ}$; yet the temperature of the skimmed milk brought to our markets, I have always found to be from 3 to 8 degrees lower than that of the atmosphere, owing to the coolness of dairies, and the effect of evaporation from the milk exposed in large surfaces to the air.

The lactometer, then, in the summer season, should not sink in genuine skimmed milk below 0 , except in cases when the weather is very hot, when it might fall to about 2 or 3 degrees below 0 . In the autumn and spring, the temperature being much lower than in the summer, the density of the milk will of course be increased, and the instrument should rise in it from about 3 to 6 degrees above 0 . In the winter, in like manner, from a further diminution of temperature, there will se a proportionate increase of density in the milk, and the lactometer should rise in it from about 7 degrees to about 10 degrees above 0 , or to the bulb. Now, I think, frauds could not be practised to any extent, in the sale of skimmed milk, without detection, if the lactometer, fig. 1, were employed, and a little attention paid to what has been given in explanation of it; yet, as the temperature is very variable in the different seasons, the use of a thermometer is very desirable, especially in cases where the lactometer is employed in markets. 'The additional expense is only about four shillings, and the trouble would be very little; for the trial of the temperature of a single churn of milk, would furnish indications nearly accurate with regari to all the others. In all cases in which adulterated milk may be seized by the proper authority, the temperature of each churn should be carefully noted down; for too much attention cannot be paid to accuracy, wherever property is liable to be forfeited.

The vacant space above 0 , in the lactometer, fig. 1 , should be filled up by extending the scale 10 degrees, as is represented in fig. 4 , which will adapt the instrument to all temperatures from $30^{\circ}$ of Fah. to $60^{\circ}$ and upwards; each degree on the scale being 
equal to the expansion occasioned by $3^{\circ}$ of Fah. It is not necessary that the scale of the lactometer should extend to $35^{\circ}$ below 0 , as in fig. 1. In some of the instruments which have been made for the markets, the scale has only reached to $25^{\circ}$, which seems quite sufficient.

I have found a considerable degree of uniformity in the density of a number of specimens of new milk, which I examined. i have male several experiments in the hope of being able to apply a similar instrument to detect the frauds practised in the sale of new milk; but I fear this is impracticable, because both water and skimmed milk are employed to adulterate new milk; and as the one is lighter and the other heavier than new milk, there would be no difficulty in so proportioning both, as to make the adulterated correspond with genuine new milk in density.

Royal Cork Institution, Sept. 17, 1821.

LIII. Description of a new Method of forming Crucilles. By Mr. Charles Cameron, Glasgow*.

T

T н $\mathrm{E}$ Dutch have long enjoyed an almost exclusive monopoly in the manufacture of the small melting-pot, or clay crucible, used by the jeweller and silversmith. The English potter has hitherto failed in imitating those imported from Holland, either in point of shape or quality, in sustaining the sudden transitions of temperature to which they are subjected. In consequence of their superiority, they were an article of great interest to the jeweller during the period of the late war; sometimes they could not be procured, and at other times they sold at five and six times their present price. 'The English melting-pot was then in request from necessity; it is now entirely out of the market. About two years ago I was led, by a curious train of reasoning, to conceive the practicability of forming crucibles similar to the Dutch, by a simple method, that of moulds made of sulphate of lime or stucco, which would easily give any required form.

I established a small manufactory of them, and carried it on for some time; but owing to particular circumstances, I was obliged to relinquish it, after it had arrived at a state of perfection. Having found it to be the opinion of my friends that the process should not be lost, I have been induced to draw up the following account of it for the Edinburgh Philosophical Journal.

For each of the different sizes of the crucibles, I formed ten or twelve dozen of moulds of stucco, burnt and powdered in the usual inanner. For the first mould of each size, I formed a piece

* From the Edinburgh Philosophical Journal. 